\title{
DELIMITAÇÃO DE MICRORREGIÕES AGROCLIMÁTICAS E SUAS RELAÇÕES COM O POTENCIAL PRODUTIVO DA CULTURA DO EUCALIPTO
}

\author{
Carlos Alexandre Damasceno Ribeiro ${ }^{1}$, José Ricardo Macedo Pezzopane ${ }^{2}$, \\ José Eduardo Macedo Pezzopane ${ }^{3}$, Rodolfo Araújo Loos ${ }^{4}$, Alexandre Cândido Xavier ${ }^{5}$, \\ Roberto Avelino Cecílio ${ }^{5}$, Mirna Aparecida Neves ${ }^{6}$ \\ ${ }^{1}$ Eng. Florestal, M.Sc., Doutorando em Produção Vegetal, UFES, Alegre, ES, Brasil \\ ${ }^{2}$ Eng. Agrônomo, Dr., EMBRAPA Pecuária Sudeste, São Carlos, SP, Brasil - jricardo @ cppse.embrapa.br \\ ${ }^{3}$ Eng. Florestal, Dr., Depto. de Engenharia Florestal, UFES, Alegre, ES, Brasil - jemp@cca.ufes.br \\ ${ }^{4}$ Eng. Agrônomo, Dr., Fibria S.A., Aracruz, ES, Brasil - raloos@ fibria.com.br \\ ${ }^{5}$ Eng. Agrícola, Dr., Depto. de Engenharia Florestal, UFES, Alegre, ES, Brasil - roberto.cecilio@ufes.br; xavier@cca.ufes.br \\ ${ }^{6}$ Geóloga, Dra ${ }^{\mathrm{a}}$., Depto. de Engenharia Rural, UFES, Alegre, ES, Brasil - mirna@ cca.ufes.br
}

Recebido para publicação: 10/07/2010 - Aceito para publicação: 29/06/2011

\begin{abstract}
Resumo
O objetivo desta pesquisa foi delimitar zonas agroclimáticas homogêneas propícias ao cultivo da cultura do eucalipto. A área estudada abrange do extremo sul da Bahia à região central-serrana do Espírito Santo. A partir de dados de temperatura e pluviosidade de 64 estações meteorológicas, foi calculado o balanço hídrico sequencial decendial, para estimativa da evapotranspiração potencial (ETP), evapotranspiração real (ETR), índice de satisfação de necessidade por água (ISNA = ETR/ETP) e índice de satisfação por necessidade de água com base em análise frequencial de ocorrência de valores superiores a 0,65 (ISNA65). Por espacialização, foram gerados mapas das médias anuais dessas variáveis e dos períodos seco e chuvoso da área de estudo, a partir da seleção dos interpoladores de maior capacidade preditiva, eleitos por validação cruzada. O zoneamento foi elaborado utilizando-se análise de agrupamento, a partir das variáveis ISNA65, ETR do período seco e temperatura média anual. A zona litorânea apresentou as melhores condições agroclimáticas, com os maiores valores médios de ISNA65 (67,8\%) e de ETR (391 mm), e a região oeste do Espírito Santo apresentou as piores condições agroclimáticas.

Palavras-chave: Zoneamento agroclimático; análise de agrupamento; sistema de informações geográficas; krigagem.
\end{abstract}

\begin{abstract}
Delimitation of agroclimatic microregions and its relationships with the productive potential of eucalyptus culture. The objective of this research was to delimit agroclimatic favorable zones to the cultivation of eucalyptus. The study area encloses the extreme south of Bahia State to the Espirito Santo`s central-mountainous, Brazil. Using data from 64 weather stations and based on temperature and pluviometric data, water balance was calculated, in order to estimate the variables potential evapotranspiration (ETP), actual evapotranspiration (ETR), crop water requirement index (ISNA = ETR/ETP) and crop water requirement index based on analysis of the frequency of highest values to 0,65 (ISNA65). Spatial maps were generated by the annual averages of these variables for the dry and rainy periods of the study area from the selection of interpolation of higher predictive capacity, elected by cross-validation. The agroclimatic zoning was elaborated using cluster analysis, based on the variables: ISNA65 and ETR of the dry period and annual temperature. The littoral zone wich are the best agroclimatic conditions during the dry period and is characterized by high values of ISNA65 $(67,8 \%)$ and ETR (391) and the west region of Espirito Santo, showed the worst agroclimatic conditions.
\end{abstract}

Keywords: Agroclimatic zoning; cluster analysis; geographic information system; kriging.

\section{INTRODUÇÃO}

Atualmente, o Brasil possui a maior área plantada de eucalipto (considerado o gênero Eucalyptus como um todo) no mundo, seguido por Índia, África do Sul e Portugal (SACRAMENTO NETO, 2001), sendo que o Espírito Santo e a Bahia possuem áreas com os maiores potenciais produtivos para essa 
espécie no território brasileiro (variando de 40 a $85 \mathrm{~m}$ 3/ha/ano) (ASSOCIAÇÃO BRASILEIRA DE PRODUTORES DE FLORESTAS PLANTADAS/ABRAF, 2007).

Apesar das condições favoráveis para a cultura do eucalipto nessa região, estudos mais detalhados são fundamentais, devido à sazonalidade climática, que, ao se considerar o plantio como etapa silvicultural crítica, deve ser criteriosamente planejada, para que haja sobrevivência e estabelecimento da muda com sucesso. A produtividade florestal está intrinsecamente relacionada à disponibilidade hídrica e aos efeitos consequentes da falta de água na planta, como diminuição da taxa fotossintética (VOSE; SMANK, citados por SOUZA et al., 2006) e diminuição do aporte nutricional das árvores (SANDS; MULLIGAN, citados por SOUZA et al., 2006).

Nesse sentido, a delimitação de áreas com características agroclimáticas favoráveis às culturas florestais, realizada pelo zoneamento agroclimático, torna-se imprescindível em regiões destinadas à silvicultura. Como ferramenta de planejamento, o zoneamento também é utilizado na organização das equipes de trabalho e na distribuição de equipamentos e máquinas no espaço e no tempo, otimizando o uso dos recursos.

Estudos sobre zoneamento agroclimático baseiam-se, sobretudo, nas variáveis chuva e temperatura do ar. Essas variáveis estão diretamente relacionadas com a energia e água disponível à planta para processos fisiológicos fundamentais para o seu crescimento, como fotossíntese e evapotranspiração (PEZZOPANE et al., 2006). Em estudos agroclimáticos, a relação entre esses elementos meteorológicos não é direta, pois não é possível afirmar, analisando somente essas variáveis, se há água disponível à planta e em quantidade suficiente. Assim, o balanço hídrico, ferramenta que contabiliza o armazenamento de água no solo, torna-se uma ferramenta mais utilizada na determinação da disponibilidade hídrica de uma região (DOORENBOS; KASSAN, 1979). A partir da obtenção de variáveis do balanço, um dos critérios mais utilizados para a estimativa da disponibilidade hídrica é o índice de satisfação das necessidades de água (ISNA), definido pela relação entre a evapotranspiração real e a evapotranspiração da cultura. Esse índice tem sido utilizado pelo Ministério da Agricultura, Pecuária e Abastecimento (MAPA) para as principais culturas comerciais agronômicas brasileiras desde 1995 (FARIA et al., 1997).

Diversos autores já trabalharam com análise frequencial do ISNA para culturas agronômicas, visando atender aos critérios do MAPA (CUNHA, 2001; MACEDO et al., 2001), sendo estabelecidos nesses casos valores empíricos para a cultura da soja, considerados "favoráveis ao desenvolvimento" (acima de 0,65), "intermediários" (valores de 0,55 a 0,65) e "de alto risco de perda agrícola" (abaixo de 0,45 ), existindo ainda outros valores para outras culturas, sempre com classes compreendidas entre 0,35 e 0,65, como Maluf et al. (2001) para a cultura do feijão e Sans et al. (2001) para a cultura do milho.

Porém nenhum desses autores trabalhou com culturas florestais. Espécies florestais, como o eucalipto, possuem necessidades diferentes daquelas próprias às culturas agronômicas. Em culturas agronômicas, a falta de água pode implicar perda total da produtividade, o que de fato ocorre raramente na cultura do eucalipto. Isso, entretanto, não significa que o plantio do eucalipto possa ser executado em qualquer período do ano ou que a produtividade seja indiferente às condições agroclimáticas.

Avanços computacionais dos Sistemas de Informações Geográficas (SIG's), desde a década de 1970, em especial no tratamento dos dados e na concepção e melhoria das suas ferramentas de análise espacial, estatísticas, como a análise de agrupamento, e geoestatísticas como a krigagem, permitiram grande evolução metodológica nos estudos de zoneamento agroclimático, sem perder o vínculo com o sólido modelo conceitual que é o balanço hídrico. Houve assim, gradativamente, a junção de um clássico modelo conceitual a essa nova ferramenta computacional.

A cartografia digital ou o geoprocessamento são ciências aplicadas, recentemente, em estudos voltados ao zoneamento agroclimático e permitem o desenvolvimento de metodologias não utilizadas em tempos passados (ASSAD et al., 2001), sobretudo em estudos realizados há mais de 20 anos. A categoria de aplicativo computacional dedicada a essas tarefas são os Sistemas de Informações Geográficas (SIG's), que gerenciam a informação visual em associação com um banco de dados.

Uma das aplicações principais de um SIG em zoneamento agroclimático é a de transformar dados numéricos obtidos em estações meteorológicas com coordenadas conhecidas (georreferenciadas) em superfícies contínuas (mapas), gerando informações a respeito do comportamento espacial da variável (CÂMARA; MEDEIROS, 1998) em escala local, regional ou estadual, variando no tempo. Esse processo é denominado interpolação, podendo ser realizado, por exemplo, pela técnica da geoestatística. O fato é que cada observação é descrita não apenas pelo seu valor, mas também pelas informações de sua posição, e parcialmente, predito pelos valores dos pontos vizinhos que não são estocasticamente independentes, como explica Ribeiro Júnior (1995). 
A geoestatística, considerada atualmente como um tópico da estatística aplicada, interpreta os fenômenos naturais através de modelos numéricos que apresentam um valor definido a cada ponto no espaço, de tal forma que pontos próximos apresentam valores mais semelhantes do que pontos distantes (LANDIM, 2003), representando mais coerentemente fenômenos como chuva e temperatura, que variam de forma não aleatória, no espaço e no tempo. É nesse contexto metodológico e computacional que as estimativas de saída provenientes do BH têm sido analisadas.

Nesse sentido o presente estudo tem como objetivo delimitar microrregiões agroclimáticas e relacioná-las à cultura do eucalipto, na região central e norte do estado do Espírito Santo e extremo sul da Bahia, a partir de variáveis do balanço hídrico, utilizando ferramentas estatísticas e geoestatísticas em um sistema de informações geográficas.

\section{MATERIAL E MÉTODOS}

A área de estudo compreende a porção central e norte do estado do Espírito Santo e o extremo sul da Bahia, região contida entre as latitudes $17^{\circ} 47^{\prime} 10^{\prime \prime} \mathrm{S}$, no sul da Bahia, e $20^{\circ} 2410^{\prime \prime} \mathrm{S}$, na região central do Espírito Santo, e entre as longitudes $41^{\circ} 19^{\prime} 00^{\prime \prime}$ W e $39^{\circ} 18^{\prime} 18^{\prime \prime} \mathrm{W}$. Os tipos climáticos da região são A e C, com os subtipos Aw, Am, Cf, Cw e as variações Cfa, Cfb e Cwa, pela classificação de Köppen (CASTRO, 2008).

Foram utilizados dados diários de precipitação pluviométrica de 64 estações meteorológicas, adquiridos junto à Agência Nacional das Águas (ANA) (http://hidroweb.ana.gov.br), Instituto Capixaba de Pesquisa e Extensão Rural (INCAPER) e FIBRIA S.A., todos por meio de consulta direta ao banco de dados. Na figura 1 é apresentado um fluxograma da metodologia empregada na presente pesquisa.

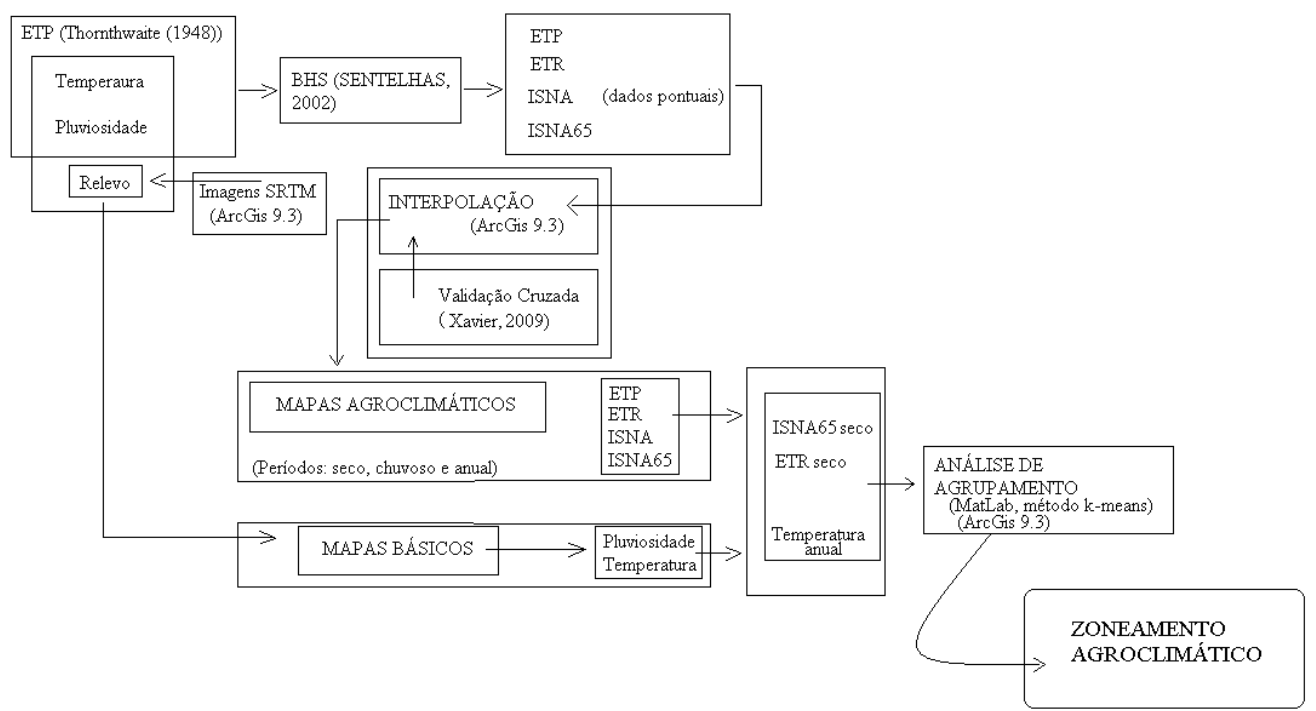

Figura 1. Fluxograma ilustrativo do esquema metodológico com as etapas realizadas para obtenção do zoneamento agroclimático.

Figure 1. Flowchart illustrating the methodological steps taken to obtain the agroclimatic zoning.

Inicialmente, os dados de precipitação pluviométrica foram tabulados em planilha eletrônica, utilizando-se da automatização possibilitada pela linguagem em Visual Basic (macros). Esse método também foi utilizado para tabulação dos dados de temperatura oriundos das estações meteorológicas da FIBRIA, dos quais foram obtidas as médias decendiais a partir de valores mensais, sendo que para os demais dados de temperatura os decêndios foram tabulados a partir de modelos de regressão desenvolvidos por Castro (2008).

De posse das coordenadas geográficas das estações e com a obtenção dos decêndios para temperatura, a ETP foi obtida pelo método de Thornthwaite (1948), utilizando-se o programa BHSeq V 6.32002 (ROLIM et al., 2002) em planilha eletrônica. No mesmo aplicativo, esses dados de temperatura, pluviosidade e ETP possibilitaram o cálculo do balanço hídrico sequencial (BHS), utilizando-se a capacidade de água disponível $(\mathrm{CAD})=300 \mathrm{~mm}$, obtendo-se assim ETR, ISNA (relação ETR/ETP) e 
ISNA65 (análise frequencial da relação ETR/ETP > 0,65) para cada estação meteorológica de forma discreta (pontual). O limite de ISNA $(0,65)$ foi baseado em Souza et al. (2006).

O melhor interpolador para espacialização de cada uma das variáveis foi determinado considerando-se os períodos seco e chuvoso pelo método da validação cruzada proposta por Robinson e Metternicht (2006), implementado em algoritmo sob a plataforma MatLab (XAVIER et al., 2010). Os interpoladores avaliados foram krigagem ordinária (considerando-se os modelos semivariograma teórico esférico, linear, gaussiano e exponencial) e o inverso das distâncias elevada às potências de $1 \mathrm{a} 5$. A espacialização das variáveis foi realizada a partir do interpolador que resultou no melhor índice de confiança (c) dos dados da tabulação cruzada (CAMARGO; SENTELHAS, 1997).

Para a análise de agrupamento final, que delimitou as áreas de cada zona com suas respectivas características agroclimáticas, considerou-se um pixel (menor elemento da imagem) de $1 \mathrm{~km}^{2}$, o que resultou em uma matriz com 61.600 linhas e 3 colunas (variáveis: ISNA65 período seco, temperatura anual e ETR do período seco). A análise de agrupamento não hierárquica convergente foi realizada com base nos seguintes critérios: (i) método convergente de agrupamentos k-means; (ii) centro de classes indefinidos; (iii) definição do número de zonas; e (iv) análise de verossimilhança com a realidade de campo, procedimento corrente em análises de agrupamento (ACOSTA, 1997).

\section{RESULTADOS E DISCUSSÃO}

Os modelos de melhor desempenho (Tabela 1) foram utilizados para interpolação e elaboração dos mapas das variáveis derivadas do balanço hídrico (ETP, ETR, ISNA e ISNA65) e para a precipitação nos períodos seco, chuvoso e anual. O método da krigagem (modelos esférico, exponencial e gaussiano) obteve melhor desempenho em relação ao inverso da distância, devido aos elevados valores apresentados no parâmetro "c", ficando evidente assim que a geoestatística melhor representou os fenômenos naturais deste estudo. Outro parâmetro importante para avaliação dos modelos é o $\mathrm{R}^{2}$, o qual revela a capacidade preditiva do modelo. Também nesse parâmetro a krigagem apresentou desempenho superior. As variáveis para o período seco destacam-se pelos maiores valores de $\mathrm{R}^{2}$, variando de 0,51 para a variável ETP até 0,79 para a variável pluviosidade, ambas no período seco. Ao analisar cada variável, é possível constatar ainda que todos os modelos do período chuvoso apresentam pior desempenho, tanto pelo $\mathrm{R}^{2}$ quanto pelo índice "c", possivelmente devido à maior variabilidade dos dados no período chuvoso, o que reduz a capacidade preditiva dos modelos.

Tabela 1. Modelos de interpoladores eleitos pelo método de validação cruzada.

Table 1. Models interpolators elected by cross validation method.

\begin{tabular}{lcccccc}
\hline Variável & Interpolador & R2 & c & Co & C1 & Alcance \\
\hline ANUAL_PREC & Modelo Exponencial & 0,34 & 0,43 & 17104,34 & 27775,62 & 1,09 \\
SECO_PREC & Modelo Esférico & 0,79 & 0,83 & 2007,93 & 18438,23 & 1,77 \\
CHUVOSO_PREC & Modelo Exponencial & 0,24 & 0,31 & 8414,66 & 8408,85 & 1,72 \\
ANUAL_ETP & Inverso distância (r =1) & 0,46 & 0,53 & - & - & - \\
SECO_ETP & Modelo Esférico & 0,51 & 0,60 & 1924,93 & 4454,65 & 1,82 \\
CHUVOSO_ETP & Modelo Esférico & 0,26 & 0,37 & 5971,93 & 2401,13 & 0,80 \\
ANUAL_ETR & Modelo Exponencial & 0,31 & 0,39 & 3098,19 & 19000,45 & 0,60 \\
SECO_ETR & Modelo Esférico & 0,66 & 0,72 & 349,58 & 3941,39 & 1,53 \\
CHUVOSO_ETR & Inverso distância (r $=1)$ & 0,24 & 0,32 & - & - & - \\
ANUAL_ISNA & Modelo Exponencial & 0,45 & 0,53 & 0,00294 & 0,00618 & 1,41 \\
SECO_ISNA & Modelo Esférico & 0,59 & 0,67 & 0,01 & 0,01 & 1,77 \\
CHUVOSO_ISNA & Modelo Esférico & 0,24 & 0,33 & 0,00 & 0,00 & 1,38 \\
ANUAL_ISNA65 & Modelo Esférico & 0,34 & 0,44 & 20,01 & 159,04 & 0,42 \\
SECO_ISNA65 & Modelo Esférico & 0,60 & 0,67 & 268,75 & 598,10 & 1,77 \\
CHUVOSO_ISNA65 & Modelo Gaussiano & 0,12 & 0,08 & 92,57 & 93,07 & 1,59 \\
\hline
\end{tabular}

Após interpretação dos mapas básicos de pluviosidade e temperatura e os derivados do balanço hídrico para os períodos anual, seco e chuvoso, constatou-se que a sazonalidade climática é acentuada, 
com o período seco (variando de abril a setembro) apresentando condições pouco favoráveis ao plantio e acúmulo de biomassa para a cultura do eucalipto.

A sazonalidade climática para a região de estudo fica caracterizada ao serem analisados os mapas básicos de temperatura ilustrados na figura 2A e figura 2B. A variável temperatura média representada nessas figuras apresenta valores mínimos com diferenças de até $4{ }^{\circ} \mathrm{C}$ a mais e variações nas temperaturas máximas de até $3{ }^{\circ} \mathrm{C}$ no período chuvoso em relação ao período seco.

Predominam temperaturas elevadas na região litorânea, incluindo a região de Tabuleiros, no entorno do município de Linhares, e temperaturas mais amenas na região elevada do interior (serrana), próxima ao município de Domingos Martins, tendência que perdura do período seco até o chuvoso, indicando assim a forte influência do relevo sobre a variável temperatura.
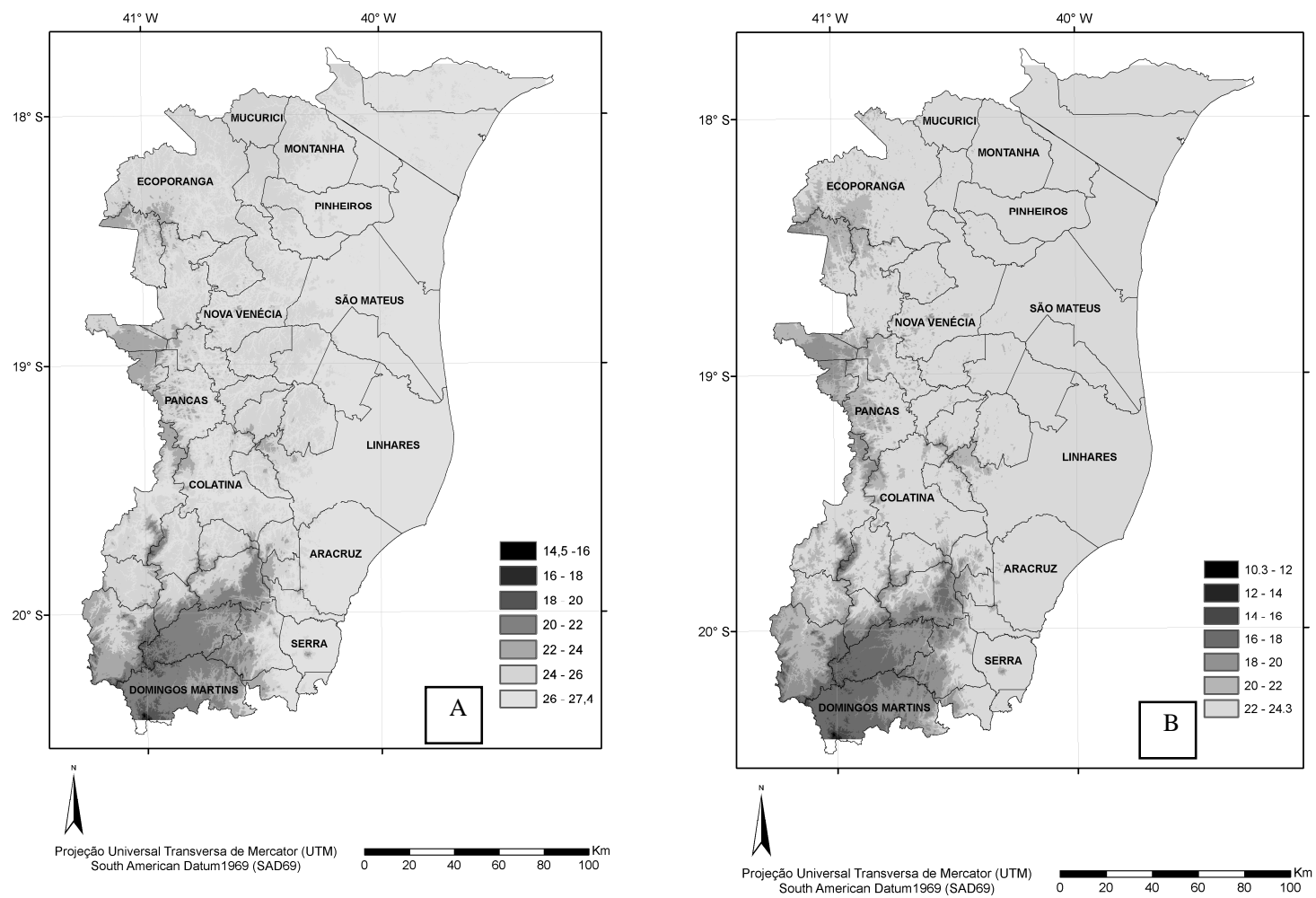

Figura 2. Espacialização das estimativas dos valores da temperatura média do ar para os períodos seco (abril a setembro - 2A) e chuvoso (outubro a março - 2B) na área em estudo.

Figure 2. Spatialization of estimates values of the average air temperature for the dry (April to September - 2A) and rainy periods (October to March - 2B) in the study area.

O entendimento da sazonalidade climática da região é discutido com base em algumas interpretações a partir das variáveis ISNA65 e ETR para o período seco. Enquanto o ISNA65 indica a frequência de decêndios com valores favoráveis (acima de 0,65 ) à cultura do eucalipto, altos valores de ETR indicam que houve pluviosidade e temperatura em quantidades satisfatórias ao acúmulo de biomassa. Essas variáveis foram utilizadas na análise de agrupamento que culminou no zoneamento agroclimático. O mapa agroclimático de ISNA65 e ETR para o período seco (Figura 3A e 3B) apresenta baixos valores nesse período.

A área com frequência de ISNA65 variando de 25 a 60 (Figura 3A), que abrange a parte oeste e central da área de estudo, apresenta um limitado potencial produtivo do eucalipto, pois nessa região o ISNA fica acima de 0,65 em menos de $40 \%$ dos decêndios analisados, o que não é desejável. Ou seja, nessa região, na série de 360 decêndios analisados (20 anos), o ISNA65 ocorreu em menos de $60 \%$ dos casos (ou seja, no máximo 216 decêndios foram atendidos por uma condição satisfatória de ISNA, considerada como 0,65 - ISNA65). Considerando que essa tendência se mantenha, o máximo potencial 
produtivo do eucalipto não pode se expressar devido à ausência de condições agroclimáticas favoráveis em pelo menos $60 \%$ do tempo necessário ao estabelecimento da cultura, desenvolvimento e acúmulo de biomassa, o que traz sérios danos à produção, sobretudo quando se pretende produzir em escala industrial.

Por outro lado, a região que abrange o extremo sul da Bahia e a região central-serrana, que abrange do município de Domingos Martins até Aracruz, possibilita as melhores condições de desenvolvimento da cultura do eucalipto, por ocorrer naquela região uma frequência superior a $80 \%$ dos decêndios com valores de ISNA superiores a 0,65.

Na figura 3B é possível observar que o extremo sul da Bahia, bem como o extremo norte do Espírito Santo, até o nordeste do município de São Mateus, apresenta altos valores de ETR (variando de 400 a $475 \mathrm{~mm}$ ), indicando que mesmo no período seco, caracterizado por valores menores de pluviosidade e temperatura, há disponibilidade hídrica e energética para efetivação da evapotranspiração.
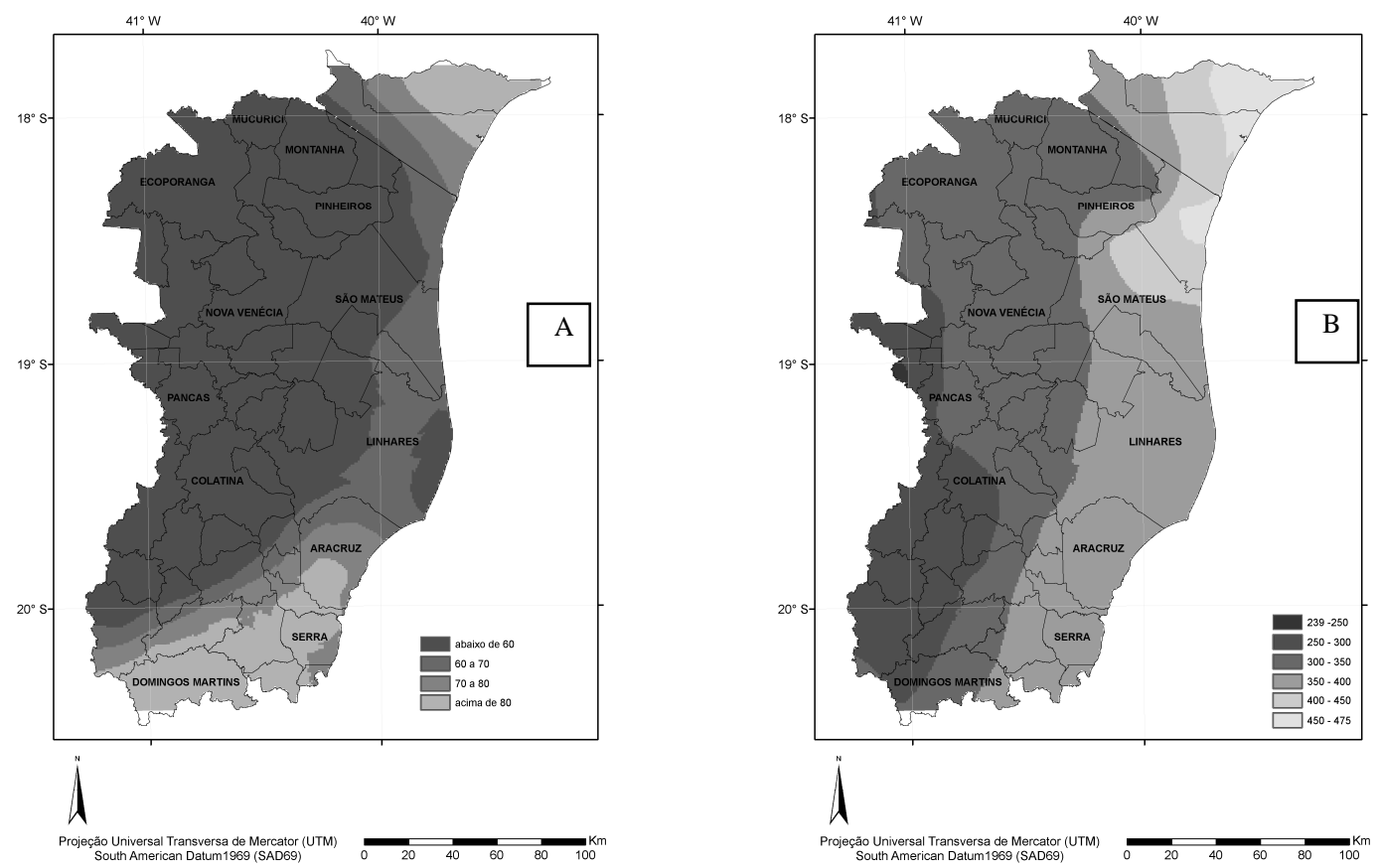

Figura 3. Espacialização do ISNA65 para o período seco (abril a setembro - 3A) e da ETR para o período seco (3B).

Figure 3. Spatialization of the ISNA65 for the dry period (April to September - 3A) and of ETR for to dry period (3B).

O extremo oeste da área em estudo apresenta os menores valores de ETR (239 a $300 \mathrm{~mm})$. A região litorânea, do município de Vitória a São Mateus, apresenta áreas com valores de ETR variando de 350 a $400 \mathrm{~mm}$, nas quais o potencial produtivo para a cultura do eucalipto não é favorável, porém propicia um razoável desenvolvimento em escala industrial.

Pelas interpretações e resultados expostos, é verdadeiro afirmar que, de forma geral, o período seco é pouco favorável ao plantio e estabelecimento do eucalipto na maior parte da área de estudo (área que abrange o todo o noroeste, oeste e sudoeste, Figura 3A). Como medidas mitigatórias, pode-se planejar irrigação após os plantios nessas áreas durante o período seco, ou plantios com gel retentor de umidade nas covas (LOOS, 2009).

Esses valores críticos representam uma limitação ao potencial da cultura (LOOS, 2009). Entretanto, é importante ressaltar que a produtividade nas áreas onde o período seco é desfavorável não chega a ser antieconômica. Exemplos de baixa produtividade são constatados em talhões situados na região sul do município de São Mateus. Nessas localidades há registros de produtividades significativamente menores do que as alcançadas em municípios como Aracruz (LOOS, 2009), onde o ISNA65 é favorável em $80 \%$ dos decêndios no período seco. 


\section{Zoneamento agroclimático}

Com base nas variáveis ETR e ISNA65 para o período seco e ainda na temperatura média anual, foi elaborado o zoneamento com 4 zonas agroclimáticas distintas (Tabela 2 e Figura 4). A zona 4 é a que mais favorece o potencial produtivo do eucalipto e abrange as regiões do extremo sul da Bahia e a região central-serrana do Espírito Santo, regiões que apresentaram os maiores valores de ETR e ISNA65. A expressão do máximo potencial de desenvolvimento do eucalipto é restringida conforme o número da zona diminui, de tal forma que a zona 1 é a que menos favorece o desenvolvimento da cultura do eucalipto durante o período seco, zona que compreende áreas nas quais os mapas agroclimáticos apresentaram os menores valores de ETR e ISNA65 (e pluviosidade).

Tabela 2. Zonas homogêneas referentes ao zoneamento agroclimático.

Table 2. Homogeneous zones for the agroclimatic zoning.

\begin{tabular}{lccccc}
\hline \multirow{2}{*}{ Zona } & Valores & ISNA65 $(\boldsymbol{\%})$ & ETR & Temperatura & \multirow{2}{*}{$\begin{array}{c}\text { Área total } \\
\mathbf{k m}^{\mathbf{2}}\end{array}$} \\
\cline { 2 - 5 } 1 & Seco & Seco $(\mathbf{m m})$ & Anual $\left({ }^{\mathbf{C}} \mathbf{C}\right)$ & \\
& mínimo & 24,86 & 239,71 & 17,2 & 2.762 \\
\hline \multirow{3}{*}{2} & máximo & 93,13 & 304,67 & 25,61 & \\
& média & 44,2 & 282,14 & 23,69 & 8.096 \\
\hline \multirow{3}{*}{3} & mínimo & 32,91 & 297,6 & 13,14 & \\
& máximo & 94,4 & 331,34 & 25,47 & 5.716 \\
\hline \multirow{3}{*}{4} & média & 49,53 & 316,69 & 23,73 & 16,88 \\
& mínimo & 41,69 & 325,54 & 25,45 & 19.807 \\
\hline
\end{tabular}

Zona 1

As áreas contidas na zona 1 totalizam $2.762 \mathrm{~km}^{2}$ e compreendem a região localizada no extremo oeste do estado do Espírito Santo, divisa com o estado de Minas Gerais. O estabelecimento da cultura (plantio e três meses seguintes) na zona abrangida pelo grupo 1 deve ser analisado com muito critério, devido aos baixos valores médios de ISNA65 $(44,2 \%)$ e ETR $(282,1)$ durante o período seco naquelas áreas. Apesar do valor médio de ISNA65 apresentar-se acima de 40\%, há ocorrência de valores mínimos abaixo desse limiar, o que se considera desfavorável à cultura do eucalipto.

Zona 2

Totaliza $8.096 \mathrm{~km}^{2}$ e caracteriza-se por ser uma zona mais semelhante ao grupo 1 em relação às demais zonas, sob o aspecto agroclimático com influências do relevo, contendo em suas áreas altitudes intermediárias, variando de 300 a 800 m (áreas em torno do município de Ecoporanga), e elevadas, com altitudes de 800 a $1700 \mathrm{~m}$ (áreas ao sudoeste de Domingos Martins), apresentando, em função dessas elevadas altitudes, valores mínimos de temperatura (aproximadamente $13{ }^{\circ} \mathrm{C}$ ) inferiores àqueles apresentados pelo grupo 1. Porém apresenta valores médios de ISNA65 (aproximadamente 49,5\%), bem como de ETR (aproximadamente $316,7 \mathrm{~mm}$ ), superiores aos apresentados pelo grupo 1, e é, sob o ponto de vista agroclimático, mais favorável para o desenvolvimento da cultura do eucalipto. Entretanto, ocorrem decêndios com valores de ISNA65 inferiores a 40\% e valores mínimos de ETR inferiores a $300 \mathrm{~mm}$.

Zona 3

O grupo 3 totaliza $5.716 \mathrm{~km}^{2}$ e caracteriza-se por ser uma faixa de transição entre o litoral (região mais favorável à produtividade do eucalipto, sob o ponto de vista agroclimático e também em relação à declividade do terreno) e o extremo oeste do estado do Espírito Santo, caracterizado como área menos favorável ao potencial produtivo do eucalipto, de forma geral.

Nesse grupo, o valor médio de ISNA65 é de 60,5\%, o que é um resultado positivo, pois, além de esse valor incluir-se na classe que varia de 60 a $80 \%$ de frequência de decêndios acima do valor 0,65 
(ISNA65) e os seus valores mínimos não atingirem menos que $40 \%$, crítico ao desenvolvimento do eucalipto, seus valores mínimos de ETR apresentam-se superiores a $300 \mathrm{~mm}$ durante o período seco.

Esses valores conferem ao grupo 3 características de zona agroclimática mais favorável ao desenvolvimento do eucalipto durante o período seco, quando comparado às zonas agroclimáticas das zonas 1 ou 2.

Zona 4

É a maior, com uma área superior a $19.800 \mathrm{~km}^{2}$. Durante o período seco, a frequência de ocorrência do ISNA65 alcança valor médio de $67,83 \%$, e é por isso a zona mais favorável ao desenvolvimento da cultura do eucalipto durante o período seco.

Vale ressaltar que os valores máximos de ETR (472 mm) e ISNA65 (93\%) apresentam-se no extremo sul da Bahia, região quente e de elevada pluviosidade durante todo ano, e valores próximos são encontrados na região central-serrana do Espírito Santo, região de temperaturas mais amenas em relação ao sul da Bahia e de elevada pluviosidade durante todo o ano. Regiões que, apesar de apresentarem diferentes valores de altitude, ETP, ETR e temperatura, apresentam valores semelhantes de ISNA e ISNA65, devido à semelhante proporcionalidade entre ETR e ETP (ISNA) e devido à elevada frequência (durante todo o ano superior a 80\%) de decêndios com valores de ISNA superiores a 0,65 (classe de ISNA65 mais favorável ao desenvolvimento da cultura do eucalipto).

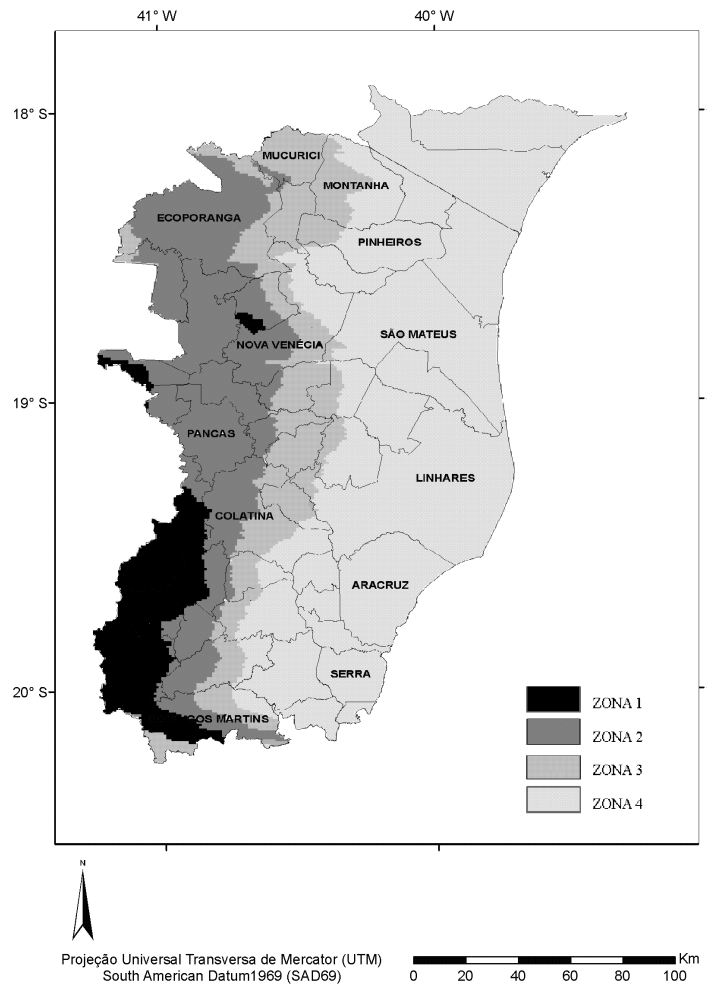

Figura 4. Zoneamento agroclimático relacionado à cultura do eucalipto a partir da análise de agrupamento.

Figure 4. Agroclimatic zoning related to the cultivation of eucalyptus from the cluster analysis.

\section{CONCLUSÕES}

- Com base na análise de agrupamento realizada, a área abrangida pela presente pesquisa possui quatro zonas agroclimáticas distintas, sendo possível realizar inferências em cada uma delas sobre o potencial produtivo para a cultura do eucalipto. 
- A zona litorânea do Espírito Santo apresentou as melhores condições agroclimáticas, com os maiores valores médios de ISNA65 $(67,8 \%)$ e de ETR $(391 \mathrm{~mm})$, e a região oeste do estado apresentou as piores condições agroclimáticas.

- O zoneamento agroclimático produzido é útil ao pleno entendimento das condições agroclimáticas na área de estudo, servindo ao planejamento das práticas silviculturais ao longo do tempo, à organização e planejamento dos recursos humanos e materiais e à indicação de áreas com maior potencial produtivo para a cultura do eucalipto.

\section{AGRADECIMENTOS}

À empresa FIBRIA S.A., por concessão de bolsa de incentivo à pesquisa em nível de mestrado ao Programa de Pós-Graduação em Produção Vegetal do Centro de Ciências Agrárias da Universidade Federal do Espírito Santo (CCA/UFES), da qual usufruiu o primeiro autor deste artigo durante a elaboração de sua dissertação. Ao Pesquisador Dr. Rodolfo Araújo Loos, funcionário da FIBRIA S.A., pela atenção especial e colaboração direta.

Ao Instituto Capixaba de Pesquisa, Assistência Técnica e Extensão Rural (INCAPER), por permitir o acesso aos dados diários de pluviosidade e temperatura. Ao pesquisador Dr. José Geraldo, funcionário daquela instituição, pela atenção especial e colaboração direta.

\section{REFERÊNCIAS}

ACOSTA, V. H. Classificação ecológica do território brasileiro situado ao sul do paralelo $\mathbf{2 4}^{\circ} \mathbf{S}$ uma abordagem climática. 86 p. Tese (Mestrado em Ciência Florestal) - Universidade Federal de Viçosa, Viçosa, 1997.

ASSAD, E. D.; EVANGELISTA, B. A.; SILVA, F. M. S.; CUNHA, S. A. R.; ALVES, E. R.; LOPES, T. S. S.; PINTO, H. S.; ZULLO JR., J. Zoneamento agroclimático para a cultura de café (Coffea arabica L.) no estado de Goiás e sudoeste do estado da Bahia. Revista Brasileira de Agrometeorologia, v. 9, n. 3, p. $510-518,2001$.

ASSOCIAÇÃO BRASILEIRA DE PRODUTORES DE FLORESTAS PLANTADAS (ABRAF). Anuário Estatístico da ABRAF. Brasília, 2007. 81 p.

CÂMARA, G.; MEDEIROS, J. S. de. Princípios básicos em geoprocessamento. In: ASSAD, E. D.; SANO, E. E. (Ed.). Sistema de informações geográficas: aplicações na agricultura. Brasília: EMBRAPA - CPA, 1998. p. 1 - 11.

CAMARGO, Â. P.; SENTELHAS, P. C. Avaliação do desempenho de diferentes métodos de estimativa da evapotranspiração potencial no estado de São Paulo, Brasil. Revista Brasileira de Agrometeorologia, Santa Maria, v. 5, n. 1, p. 89 - 97, 1997.

CASTRO, F. da S. Zoneamento agroclimático para a cultura do Pinus no estado do Espírito Santo. Dissertação (Mestrado em Produção Vegetal) - Universidade Federal do Espírito Santo, Espírito Santo 2008.

CUNHA, G. R. Zoneamento agrícola e época de semeadura para trigo no Brasil. Revista Brasileira de Agrometeorologia, Passo Fundo, v. 9, n. 3, p. 400 - 414, 2001. (Número Especial - Zoneamento Agrícola).

DOORENBOS, J.; KASSAM, A. H. Yield response to water. Rome: Food and Agriculture Organization of the United Nations, 1979. 193 p. (Irrigation and Drainage, Paper 33).

FARIA, R. T. de; FOLEGATTI, M. V.; OLIVEIRA, D. de. Crescimento e desenvolvimento do feijoeiro sob diferentes regimes térmicos e hídricos. In: CONGRESSO BRASILEIRO DE AGROMETEOROLOGIA, 10., 1997, Piracicaba. Anais... Piracicaba, SP: Universidade de São Paulo, Escola Superior de Agricultura "Luiz de Queiroz", 1997. p. 659 - 661.

LANDIM, P. M. B. Análise estatística de dados geológicos. UNESP, 2003. 253 p. 
LOOS, R. A. Análise da veracidade entre os agrupamentos elaborados e os dados de campo. Aracruz: Centro de Pesquisa e Tecnologia - FIBRIA S.A., 2009. Comunicação pessoal.

MACEDO, M. A. de; ASSAD, E. D.; CÂMARA, G.; OLIVEIRA, J. C.; BARBOSA, A. M. Avaliação de métodos para espacialização de índices de necessidade hídrica das culturas e sua aplicação em zoneamento agrícola. Revista Brasileira de Agrometeorologia, Passo Fundo, v. 9, n. 3, p. 581 - 586, 2001. (Número Especial - Zoneamento Agrícola).

MALUF, J. R. T.; CUNHA, G. R. da; MATZENAUER, R.; PASINATO, A.; PIMENTEL, M. B. M.; CAIAFFO, M. R.; PIRES, J. L. F. Zoneamento de riscos climáticos para a cultura de milho no Rio Grande do Sul. Revista Brasileira de Agrometeorologia, Passo Fundo, v. 9, n. 3, p. 460 - 467, 2001. (Número Especial - Zoneamento Agrícola).

PEZZOPANE, J. E. M.; SANTOS, E. A.; SANTOS, A. R.; SILVA, G. F.; REIS, E. F. Delimitação de zonas agroclimáticas no estado do Espírito Santo. Revista Brasileira de Agrometeorologia, v. 14, n. 2, p. 149 - 156, 2006.

RIBEIRO JÚNIOR, P. J. Métodos geoestatísticos no estudo da variabilidade espacial de parâmetros do solo. 99 f. Dissertação (Mestrado em Agronomia) - Escola Superior de Agricultura Luiz de Queiroz, Piracicaba, 1995.

ROBINSON, T. P.; METTERNICHT, G. Testing the performance of spatial interpolation techniques for mapping soil properties. Computers and Electronics in Agriculture, p. 97 - 108, 2006.

ROLIM, G. S.; SENTELHAS, P. C.; BARBIERI, V. Planilhas no ambiente Excel $^{\mathrm{TM}}$ para cálculos de balanços hídricos: normal, sequencial, de cultura e de produtividade real e potencial. Revista Brasileira de Agrometeorologia, Santa Maria, v. 6, n. 1, p. 133 - 137, 2002.

SACRAMENTO NETO, O. B. Balanço hídrico em plantios jovens de eucalipto na região de Belo Oriente, MG. 82 f. Dissertação (Mestrado em Meteorologia Agrícola) - Universidade Federal de Viçosa, Viçosa, 2001.

SANS, L. M. A.; ASSAD, E. D.; GUIMARÃES, D. P.; AVELAR, G. Zoneamento de riscos climáticos para a cultura de milho na região centro-oeste do Brasil e para o estado de Minas Gerais. Revista Brasileira de Agrometeorologia, v. 9, n. 3, p. 527 - 535, 2001.

SOUZA, M. J. H.; RIBEIRO, A.; LEITE, H. G.; LEITE, F. P.; MINUZZI, R. B. Disponibilidade hídrica do solo e produtividade do eucalipto em três regiões da bacia do Rio Doce. Revista Árvore, Viçosa, v. 30, n. 3, p. 399 - 410, 2006.

THORNTHWAITE, C. W. An approach toward a rational classification of climate. The Geographical Review, v. 38, p. 55 - 94, 1948.

XAVIER, A. C.; CECÍLIO, R. A.; LIMA, J. S. S. Módulos em MATLAB para interpolação espacial pelo método de krigagem ordinária e do inverso da distância. Revista Brasileira de Cartografia, v. 62, p. 67 76, 2010. Online. 